\title{
Outcomes of Microsurgical Clipping in Middle Cerebral Artery Aneurysms
}

\author{
Mehmet Secer ${ }^{1(\mathbb{D})}$ Aykut Gokbel ${ }^{2(\mathbb{I D})}$ \\ ${ }^{1}$ Department of Neurosurgery, Alaaddin Keykubat University School of Medicine, Antalya, Turkey. \\ ${ }^{2}$ Neurosurgery Clinic, Derince Training and Research Hospital, Kocaeli, Turkey
}

Copyright@ Author(s) - Available online at https://dergipark.org.tr/en/pub/mbsjohs

Content of this journal is licensed under a Creative Commons Attribution-NonCommercial 4.0 International

License,

Received: 16 August 2021, Accepted: 17 September 2021, Published online: 31 December 2021

(C) Ordu University Institute of Health Sciences, Turkey, 2021

\begin{abstract}
Objective: Surgical or endovascular treatment is used in the treatment of intracranial aneurysms. Recent studies have suggested that the of endovascular treatment are superior to surgery Middle cerebral artery (MCA) aneurysm is the third most common bleeding aneurysm after anterior communicating artery and internal carotid artery aneurysms. We aimed to retrospectively evaluate the microsurgical outcomes of cases operated for MCA aneurysm.

Methods: Twenty cases with MCA aneurysm who accepted the microsurgical treatment option were included in this study. Data were obtained by retrospectively reviewing the clinical, radiological, and intraoperative findings, as well as postoperative morbidity and mortality of the cases.

Results: In total, 23 MCA aneurysms were detected in 20 cases. In 2 cases, MCA aneurysm was detected incidentally. Microsurgical clipping was performed in 23 aneurysms. In the study, the total mortality rate was $10 \%$ and the morbidity rate was $20 \%$ in MCA aneurysms.

Conclusion: It was observed that the incidence of calcification or thrombosis within the aneurysm increased and the Glasgow outcome scores at the 3rd month decreased as the width and length values of the aneurysm sac increased. In addition, presence of calcification in the aneurysm wall or thrombosis in the sac was found to be positive and strongly correlated with mortality and morbidity.

Key words: Middle cerebral artery, aneurysm, microsurgery
\end{abstract}

Suggested Citation M S, A G. Outcomes of Microsurgical Clipping in Middle Cerebral Artery Aneurysms. Mid Blac Sea Journal of Health Science, 2021; 7(3):411-415

\section{Address for correspondence/reprints:}

Mehmet Secer

Telephone number: +90 (505) 3478955

E-mail: memetsecer@yahoo.com

\section{Introduction}

Surgical or endovascular treatment is used in the treatment of intracranial aneurysms. Recent international studies have suggested that the outcomes of endovascular treatment are superior to surgery $(1,2)$. However, microsurgical clipping is the first treatment option in most centers since middle cerebral artery (MCA) aneurysms have a wide neck and middle cerebral artery branches come out of the base or body of the aneurysm $(2,3)$.

MCA aneurysms constitute $18 \%-36 \%$ of all intracranial aneurysms (3). It is the third most common bleeding aneurysm after anterior communicating artery and internal carotid artery 
aneurysms (2). This study retrospectively evaluated the microsurgery results of $23 \mathrm{MCA}$ aneurysms detected in 20 cases. Demographic findings, morphological structure of the aneurysm, calcification in the wall and thrombosis in the sac the effect of on outcome were evaluated.

\section{Methods}

We retrospectively evaluated consecutive cases operated for MCA aneurysm performed by a single surgeon (M.S). (Ethics committee number: 74-2021). Inclusion criteria for the study; rupture and nonrupture MCA aneurysm was detected and microsurgery was applied. Exclusion criteria were those who did not accept surgery for an MCA aneurysm and had endovascular treatment. Of the cases, 18 presented to the emergency department with symptoms of subarachnoid hemorrhage $(\mathrm{SAH})$ that developed after rupture of the aneurysm. Incidental MCA aneurysm was detected on MRI in 2 patients who presented to the outpatient clinic with headache. In cases of SAH and incidental detection of MCA aneurysm, computed tomographic angiography and/or digital subtraction angiography were used to evaluate the morphology and location of the aneurysm (Fig. 1). We measured and recorded the largest width and height values of the aneurysm sac. Patients who presented following SAH were admitted to the intensive care unit.

\section{Statistical analysis}

Statistical analysis was performed using the SPSS version 25.0 for Windows (Armonk, NY: IBM Corp.). The normality of the distribution of the data was analyzed by the Shapiro Wilk test. The relationship between variables was evaluated using the Spearman correlation analysis. The results were presented as numbers (percentages) and mean \pm standard deviation. Results with a $\mathrm{p}$ value less than 0.05 were considered statistically significant.

\section{Results}

The cases comprised 12 women and 8 men. The mean age was $53.2 \pm 12.9$, with the youngest and the oldest patient being 14 and 70 years old, respectively. The bilateral MCA aneurysm was found in 3 cases with SAH (Fig. 2). Morphologically; 17 aneurysms were small in size (smaller than $15 \mathrm{~mm}$ ), one aneurysm was large $(20 \times 23 \mathrm{~mm}), 2$ aneurysms had a giant size $(48 \times 34 \mathrm{~mm}$ and $30 \times 34 \mathrm{~mm})$ and partial thrombosis, and 2 aneurysm walls had calcified. Clinical, radiological, intraoperative findings, postoperative morbidity, and Glasgow outcome scale (GOS) at 3 months are shown in Table-1. Emergency surgery was performed in one patient with a large temporal hematoma. Other patients were operated under the earliest elective conditions to prevent the possibility of re-bleeding.

\section{Surgical treatment:}

ECG, invasive artery and central catheters were used in each patient for intraoperative anesthesia monitoring during aneurysm surgery. Pental was used for providing neuroprotection in cases where temporary clips were used. Surgery was performed in the form of classical pterional craniotomy in cases with thrombosed giant aneurysm and hematoma, and in the form of osteoplastic pterional craniotomy in uncomplicated cases. The patient was laid in the supine position and induced general anesthesia. Next, the head was fixed in a head holder and rotated approximately 30-45 degrees to the opposite side and a pterional skin incision was performed such that the malar eminence was in the uppermost position. The dura was opened with a C-shaped incision and toppled to the front side. Then, starting from the medial Sylvian fissure and leaving the vein group on the temporal side, dissection was performed from the frontal side to reach the internal carotid artery bifurcation. Later, after M1 was prepared for proximal control, the aneurysm was dissected distally and the aneurysm was clipped using a temporary clip when necessary (Fig. 3). Thrombectomy was performed in cases where the aneurysm was thrombosed. After clipping, the proximal and distal MCA branches were checked with a micro-Doppler probe, and papaverine-impregnated gel sponges were placed in the vascular bed. The dura was sealed watertight, and then primary closure was performed of the other layers. In patients with bilateral aneurysm, a second surgery was performed one month later for non-rupture contralateral MCA aneurysm. 
Table-1: Patient demographics, characteristics of the aneurisms, and clinical outcomes.

\begin{tabular}{|c|c|c|c|c|c|c|c|c|c|c|}
\hline No & $\begin{array}{c}\text { Age } \\
\text { (years) }\end{array}$ & $\begin{array}{c}\text { Gende } \\
\mathbf{r}\end{array}$ & Side & $\begin{array}{c}\text { Size } \\
(\mathbf{m m})\end{array}$ & $\begin{array}{c}\text { Calcificati } \\
\text { on / } \\
\text { Thrombosi } \\
\text { s }\end{array}$ & Localization & $\begin{array}{c}\text { Hunt\& } \\
\text { Hess }\end{array}$ & SAH & $\begin{array}{c}\text { GOS } \\
3^{\text {rd }} \\
\text { month }\end{array}$ & Morbidity \\
\hline 1 & 70 & Female & Left & $8 \times 4$ & - & Bifurcation & Grade 1 & - & 5 & - \\
\hline 2 & 57 & Female & Left & $7 \times 5$ & - & Bifurcation & Grade 1 & + & 5 & - \\
\hline 3 & 14 & Female & Right & $5.5 \times 4$ & - & M3 & Grade 1 & + & 5 & - \\
\hline 4 & 63 & Female & Right & $5.8 \times 7.7$ & - & Bifurcation & Grade 1 & + & 5 & - \\
\hline 5 & 65 & Female & Right & $6.5 \times 5.1$ & - & Bifurcation & Grade 1 & + & 5 & - \\
\hline 6 & 70 & Female & Right & $7 \times 6$ & - & Bifurcation & Grade 1 & - & 5 & - \\
\hline 7 & 54 & Female & Right & $11 \times 10$ & Calcification & Bifurcation & Grade 1 & + & 4 & Left hemiparesis \\
\hline 8 & 53 & Male & Left & $7.3 \times 4.9$ & Calcification & Bifurcation & Grade 1 & + & 4 & Right hemiparesis \\
\hline 9 & 54 & Male & Bilateral & $6.5 \times 4 \mathrm{R}$ & $3.3 \times 2.2 \mathrm{~L}$ & - $\quad$ Bifurcation & Grade 2 & & + & 5 \\
\hline 10 & 60 & Female & Bilateral & $6 \times 5 \mathrm{R}$ & $6.4 \times 4.5 \mathrm{~L}$ & Bifurcation & Grade 2 & & + & 5 \\
\hline 11 & 35 & Female & Left & $5.2 \times 5$ & - & Bifurcation & Grade 2 & + & 5 & - \\
\hline 12 & 62 & Male & Left & $6.3 \times 4$ & - & Bifurcation & Grade 2 & + & 5 & - \\
\hline 13 & 43 & Female & Right & $4.1 \times 4$ & - & $\mathrm{M} 2$ & Grade 2 & + & 5 & - \\
\hline 14 & 52 & Male & Bilateral & $5.2 \times 3.4 \mathrm{R}$ & $1.6 \times 1.3 \mathrm{~L}$ & Bifurcation & Grade 2 & & + & 5 \\
\hline 15 & 63 & Male & Right & $48 \times 34$ & Thrombosis & Bifurcation & Grade 3 & + & 5 & Hydrocephaly \\
\hline 16 & 43 & Male & Right & $6 \times 4$ & - & Trifurcation & Grade 3 & + & 5 & - \\
\hline 17 & 45 & Female & Left & $30 \times 34$ & Thrombosis & Bifurcation & Grade 3 & + & 5 & Aphasia \\
\hline 18 & 35 & Male & Right & $20 \times 23$ & - & Bifurcation & Grade 3 & + & 1 & Fatal \\
\hline 19 & 63 & Female & Right & $5.6 \times 4.3$ & - & Bifurcation & Grade 4 & + & 5 & - \\
\hline 20 & 56 & Male & Right & $11.8 \mathrm{X} 10$ & - & Bifurcation & Grade 5 & + & 1 & Fatal \\
\hline
\end{tabular}

GOS: Glasgow outcome scale; L: left; R: right; SAH: subarachnoid hemorrhage.

\section{Surgical Outcomes:}

In a total of 20 patients, $23 \mathrm{MCA}$ aneurysms were clipped. One patient with a wide hematoma and Hunt $\&$ Hess stage 3 died due to vasospasm, and another patient with a large aneurysm (size $11.8 \times 10 \mathrm{~mm}$ ) and Hunt \& Hess stage 5 died due to vasospasm-related ischemic causes. In our case of giant thrombosed aneurysm located in the left MCA, transient aphasia resolved in the third month. Hydrocephalus developed during the first postoperative month in the other case with giant thrombosed MCA aneurysm. The hydrocephalus was treated with a ventriculoperitoneal (VP) shunt. Hemiparesis developed in 2 patients with MCA aneurysm with a calcified part. Both patients were able to mobilize without aid 3 months later with the support of physical therapy. In the study, the total mortality rate was $10 \%$ and morbidity rate was $20 \%$ in MCA aneurysms. The relationship between the

Table-2: Correlation coefficients of the variables. demographic characteristics of the patients, the radiological characteristics of aneurysms, and the surgical outcomes are presented in Table-2. Age and SAH incidence were found to be negatively correlated in the cases. $(r=-0.490 ; p=0.018)$ It was observed that Hunt \& Hess stages were higher $(\mathrm{r}=$ $0.433 ; p=0.039$ ) in the male gender. As the measured values of width and length of aneurysms increased, the incidence of calcification or thrombosis within the aneurysm increased $(r=0.571, p=0.004$ for width; $r$ $=0.498, \mathrm{p}=0.016$ for height ) and GOS scores at the 3rd month decreased $(\mathrm{r}=-0.507, \mathrm{p}=0.014$ in width; $\mathrm{r}=-0.431, \mathrm{p}=0.040$ for height), and mortality and morbidity were more common $(\mathrm{r}=0.747, \mathrm{p}<0.001$ in width; $r=0.679, p<0.001$ for height). In addition, the presence of calcification or thrombosis in the aneurysm sac as found to be positive and strongly correlated with mortality and morbidity $(r=0.772 ; p$ $<0.001)$.

\begin{tabular}{|c|c|c|c|c|c|c|c|c|c|c|}
\hline & & Male & $\begin{array}{c}\text { Right / } \\
\text { Left }\end{array}$ & Width & Height & $\begin{array}{c}\text { Calcification / } \\
\text { Thrombosis }\end{array}$ & $\begin{array}{c}\text { Hunt\&He } \\
\text { ss }\end{array}$ & SAH & $\begin{array}{c}\text { GOS } \\
3^{\text {rd }} \text { month }\end{array}$ & $\begin{array}{c}\text { Morbidity / } \\
\text { Mortality }\end{array}$ \\
\hline \multirow[t]{2}{*}{ Age (years) } & $r$ & -0.239 & -0.040 & 0.274 & 0.194 & -0.052 & -0.246 & -0.490 & 0.223 & -0.172 \\
\hline & $p$ & 0.273 & 0.855 & 0.206 & 0.376 & 0.814 & 0.257 & $0.018^{*}$ & 0.307 & 0.432 \\
\hline \multirow[t]{2}{*}{ Gender (male) } & $r$ & - & 0.016 & 0.033 & -0.260 & 0.060 & 0.433 & 0.271 & -0.310 & 0.278 \\
\hline & $p$ & - & 0.944 & 0.881 & 0.230 & 0.784 & $0.039^{*}$ & 0.212 & 0.149 & 0.199 \\
\hline \multirow[t]{2}{*}{ Right / Left } & $r$ & - & - & -0.067 & -0.251 & 0.102 & -0.142 & -0.069 & 0.153 & -0.071 \\
\hline & $p$ & - & - & 0.761 & 0.248 & 0.643 & 0.518 & 0.755 & 0.487 & 0.749 \\
\hline \multirow[t]{2}{*}{ Width (mm) } & $r$ & - & - & - & 0.759 & 0.571 & 0.077 & -0.221 & -0.507 & 0.747 \\
\hline & $p$ & - & - & - & $0.000^{* *}$ & $0.004^{* *}$ & 0.727 & 0.310 & $0.014^{*}$ & $0.000^{* *}$ \\
\hline \multirow[t]{2}{*}{ Height (mm) } & $r$ & - & - & - & - & 0.498 & 0.107 & 0.012 & -0.431 & 0.679 \\
\hline & $p$ & - & - & - & - & $0.016^{*}$ & 0.627 & 0.958 & $0.040^{*}$ & $0.000^{* *}$ \\
\hline \multirow{2}{*}{$\begin{array}{l}\text { Calcification / } \\
\text { Thrombosis }\end{array}$} & $r$ & - & - & - & - & - & 0.000 & 0.142 & -0.341 & 0.772 \\
\hline & $p$ & - & - & - & - & - & 1.000 & 0.519 & 0.112 & $0.000^{* *}$ \\
\hline \multirow[t]{2}{*}{ Hunt\&Hess } & $r$ & - & - & - & - & - & - & 0.369 & -0.117 & 0.292 \\
\hline & $p$ & - & - & - & - & - & - & 0.083 & 0.596 & 0.176 \\
\hline \multirow{2}{*}{ SAH } & $r$ & - & - & - & - & - & - & - & -0.141 & 0.183 \\
\hline & $p$ & - & - & - & - & - & - & - & 0.521 & 0.402 \\
\hline \multirow{2}{*}{$\begin{array}{l}\text { GOS 3 }^{\text {rd }} \\
\text { month }\end{array}$} & $r$ & - & - & - & - & - & - & - & - & -0.769 \\
\hline & $p$ & - & - & - & - & - & - & - & - & $0.000^{* *}$ \\
\hline
\end{tabular}

GOS: Glasgow outcome scale; SAH: subarachnoid hemorrhage. ${ }^{*} \mathrm{p}<0.05 ;{ }^{*} \mathrm{p}<0.01$. 


\section{Discussion}

The most important results of the present study are as follows. It was determined that the incidence of calcification or thrombosis in the aneurysm increased, the GOS scores at the 3rd month decreased, and mortality and morbidity were more common as the measured width and height values of the aneurysms increased. In addition, thrombosis in the aneurysm sac and calcification in the aneurysm wall were found to be positive and strongly correlated with mortality and morbidity.

Surgery for MCA aneurysm has been performed for a long time. While aneurysm occlusion at a rate of above $90 \%$ and good results at a rate of $88 \%-100 \%$ after surgery have been reported in nonbleeding aneurysms, results have been variable in bleeding aneurysms. There are still question marks and confusion as to the selection of the treatment method for MCA aneurysms (4). The International Subarachnoid Aneurysm Trial (ISAT) has reported that endovascular treatment is superior in the treatment of ruptured and no ruptured aneurysms (1). Microsurgical treatment comes to the fore in cases where the MCA aneurysms have a wide neck, are of dysmorphic shape, are located in the trifurcation, have MCA branches coming out of their base or body, are easily accessible surgically, and there is hematoma accompanying the ruptured aneurysm $(2,4)$.

Ruptured aneurysms are associated with serious morbidity and mortality rates, around $60 \%(5,6)$. In the literature, the mortality rate due to microsurgical clipping ranges from $0.3 \%$ to $13 \%(4,7)$. In our study, the mortality rate was $10 \%$ when evaluated according to the number of patients, and $8.6 \%$ when evaluated according to the number of surgeries performed. The rate of major complications in MCA aneurysm surgery is between $2 \%$ and $25 \%$ (6). In this study, morbidity was $20 \%$ based on the number of cases, and $13.0 \%$ based on the number of surgeries.

In the present study; thrombosis in the aneurysm sac, large size, and calcification in the aneurysm wall are identified as risk factors leading to morbidity and mortality. In a study by Ulutaş reporting the results of intracranial aneurysm surgery; it was reported that multiple aneurysms, high Hunt \& Hess stage, and presence of intracerebral hematoma affected morbidity and mortality (8). In our study, the lack of correlation between high Hunt \& Hess stage and morbidity and mortality was attributed to the low number of patients in high stage. Similar to the results of the study by Ulutaş, the Hunt \& Hess stage was found to be high in male patients in the present study.
In our series, no mortality or morbidity was observed in patients with multiple aneurysms with bilateral MCA aneurysm. Flamm et al. reported that morbidity is high in complex aneurysms with large size and wide neck, and calcification in the aneurysm wall (9). In our study, calcification of the aneurysm wall was detected intraoperatively in both the patients who developed postoperative hemiparesis. We believe that the difficult and long duration of clip application due to calcification contributed to the development of ischemia and hemiparesis. The patient's condition following aneurysm rupture, presence of calcification in the aneurysm wall, intraluminal thrombus, and surgical accessibility are important in determining the treatment option in MCA aneurysm (10). In addition to evacuation of intraparenchymal hematoma during microsurgical clipping, it also allows decompressive hemicraniectomy when necessary $(4,11,12)$.

The limitations of this study were the limited number of patients since it only included patients with MCA aneurysm and the failure to standardize postoperative intensive care follow-ups because it was not a controlled study.

\section{Conclusion}

In conclusion, large size of the aneurysm, presence of thrombosis in the aneurysm sac, and calcification in the aneurysm wall were found to be positive and strongly correlated with mortality and morbidity.

\section{Acknowledgments}

We would also like to thank Assoc. Prof. Dr. Hande Gurbuz from Bursa Yuksek Ihtisas Hospital Department of Anesthesiology, who helped with the statistics of this study.

Ethics Committee Approval: Appropriate permission for the study was obtained from the Committee of Ethics of Derince Training and Research Hospital (approval no: 2021-74).

Peer-review: Externally peer-reviewed.

Author Contributions: Concept: M.S, A.G Design: M.S, A.G, Literature Search: M.S, A.G, Data Collection and Processing: M.S, A.G, Analysis or Interpretation: M.S, A.G Writing: M.S.

Conflict of Interest: No conflict of interest was declared by the authors.

Financial Disclosure: The authors declared that this study hasn't received no financial support. 


\section{References}

1. Molyneux A, Kerr R, Stratton I, Sandercock P, Clarke M, Shrimpton J, Holman R: International Subarachnoid Aneurysm Trial (ISAT) of neurosurgical clipping versus endovascular coiling in 2143 patients with ruptured intracranial aneurysms: A randomised trial. Lancet 360:12671274, 2002

2. Kahilogulları G, Bozkurt M, Egemen N Middle Cerebral Artery Aneurysms: Yesterday and Today. Turkish Neurosurgery Journal 2013, Vol: 23, Number: 1, 27-39

3. Matsukawa H, Kamiyama H, Miyazaki T, Kinoshita Y, Ota N, Noda K, Shonai T, Takahashi O, Tokuda S, Tanikawa R. Surgical Treatment of Middle Cerebral Artery Aneurysms: Aneurysm Location and Size Ratio as Risk Factors for Neurologic Worsening and Ischemic Complications. World Neurosurg. 2018;117:e563e570. doi: 10.1016/j.wneu.2018.06.077

4. Rodríguez-Hernández A, Sughrue ME, Akhavan S, Habdank-Kolaczkowski J, Lawton MT. Current management of middle cerebral artery aneurysms: surgical results with a "clip first" policy. Neurosurgery. 2013;72(3):415-27.

5. Elsharkawy A, Lehečka M, Niemelä M, Kivelev J, Billon-Grand R, Lehto H, et. al. Anatomic risk factors for middle cerebral artery aneurysm rupture: computed tomography angiography study of 1009 consecutive patients. Neurosurgery. 2013;73(5):825-37; discussion 836-7

6. Hallout S. Surgical Treatment of Middle Cerebral Artery Aneurysms Without Using Indocyanine Green Videoangiography Assistance: Retrospective Monocentric Study of 263 Clipped Aneurysms. World Neurosurg. 2015;84(4):972-7.

7. Morgan MK, Mahattanakul W, Davidson A, Reid J. Outcome for middle cerebral artery aneurysm surgery. Neurosurgery. 2010; 67(3):755-61

8. Ulutas M. Intracranial aneurysm surgery outcomes: a single Center experience. Cukurova Med J 2016;41(4):732-743

9. Flamm ES, Grigorian AA, Marcovici A Multifactorial analysis of surgical outcome in patients with unruptured middle cerebral artery aneurysms. Ann Surg 2000;232:570-575
10. Washington CW, Ju T, Zipfel GJ, Dacey RG Jr. Middle cerebral artery bifurcation aneurysms: an anatomic classification scheme for planning optimal surgical strategies. Neurosurgery. 2014 Mar;10 Suppl 1:145-53; discussion 153-5

11. Mooney MA, Simon ED, Brigeman S, Nakaji P, Zabramski JM, Lawton MT, et. al. Long-term results of middle cerebral artery aneurysm clipping in the Barrow Ruptured Aneurysm Trial. J Neurosurg. 2018;130(3):895-901. doi: 10.3171/2017.10.JNS172183.

12.Ryu DS, Shim YS: Importance of hematoma removal ratio in ruptured middle cerebral artery aneurysm surgery with intrasylvian hematoma. J Cerebrovasc Endovasc Neurosurg 19:5-11, 2017 